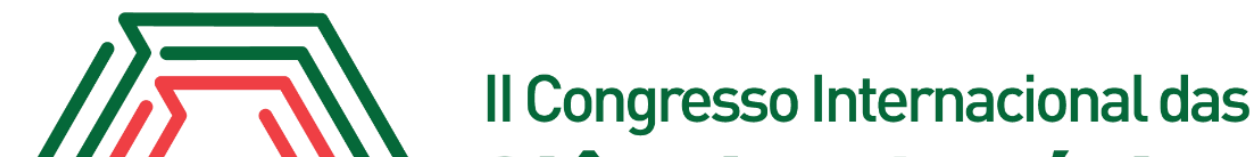 Ciências Agrárias COINTER - PDVAgro 2017
}

\section{ASPECTOS COMPORTAMENTAIS OBSERVADOS EM CORDEIROS SPRD ALIMENTADOS COM DIETAS RICAS EM GRÃO}

\author{
Apresentação: Pôster
}

\begin{abstract}
Allison Ferreira de Lima ${ }^{1}$; Hélia Maria de Souza Leite ${ }^{2}$; Jéssica Taiomara Moura Costa Bezerra de Oliveira ${ }^{3}$; Uri Vanille Raiol da Silva ${ }^{4}$ Patrícia de Oliveira Lima ${ }^{5}$
\end{abstract}

\section{Introdução}

Ao longo de décadas, a ovinocultura foi considerada uma atividade de subsistência na região Nordeste do Brasil, normalmente com baixa produtividade e realizada por produtores desprovidos de capital financeiro e de recursos tecnológicos. Entretanto, atualmente, a produção destes pequenos ruminantes vem se caracterizando como uma atividade de grande importância cultural, social e econômica para a região, desempenhando um papel crucial no desenvolvimento do Nordeste (COSTA et al., 2008).

Dessa forma, a demanda nos últimos anos, pela carne de cordeiro tem aumentado significativamente. Nessa perspectiva, dietas com altos teores de concentrados energéticos apresentam vantagens em comparação às dietas ricas em volumosos, pois são de fácil armazenagem e manejo, proporcionam rápido acabamento de carcaça e ganho de peso elevado em animais confinados (VECHIATO e ORTOLANI, 2008).

Assim, a preocupação por um manejo produtivo economicamente viável, tem gerado pesquisas na área de comportamento e bem estar animal. Dessa forma, objetivou-se, através deste trabalho, avaliar aspectos comportamentais observados em cordeiros SPRD alimentados com dietas ricas em grão.

\footnotetext{
${ }^{1}$ Mestrando em Ciência Animal, Universidade Federal Rural do Semi-Árido, henresito@ hotmail.com

${ }^{2}$ Doutora em Ciência Animal, Universidade Federal Rural do Semi-Árido, heliazootecnista@ @otmail.com

${ }^{3}$ Mestranda em Ciência Animal, Universidade Federal Rural do Semi-Árido, j.taiomara@ @otmail.com

${ }^{4}$ Mestranda em Produção Animal, Universidade Federal Rural do Semi-Árido, uri_raiol@hotmail.com

${ }^{5}$ Docente Associado I, Centro de Ciências Agrárias, Universidade Federal Rural do Semi-Árido, pattlima@ufersa.edu.br
} 


\section{Fundamentação Teórica}

O estudo do comportamento animal assume papel importante dentro da produção animal, uma vez que para racionalizar os métodos de criação foram desenvolvidas técnicas de manejo, alimentação e instalações que interferem (e também dependem) do comportamento. Assim, a Etologia pode mostrar o caminho para a racionalização da criação animal, principalmente em sistema intensivos de produção (COSTA, 1987).

Dentro dessa perspectiva, estudar o comportamento animal é de grande importância, principalmente para animais mantidos em regime de confinamento (DAMASCENO et al., 1999). A avaliação das variações do comportamento é uma ferramenta importante na utilização das dietas, pois permite ajustar o manejo alimentar dos animais para obtenção de melhores resultados de desempenho produtivo (CARDOSO et al., 2006).

Os indicadores comportamentais que têm sido avaliados nos animais em condições de estresse são: ingestão de alimento e água, ruminação, ócio e procura de sombra, sendo a redução na ingestão de alimentos, aumento na ingestão de água e a procura pela sombra respostas imediatas ao estresse pelo calor (SILANIKOVE, 2000). Diante do exposto, Costa et al. (2002) relatam que só a partir da aquisição desse conhecimento estaremos mais bem preparados para definir técnicas de criação e de manejo, atendendo aos interesses econômicos, sem prejudicar o bem-estar animal.

\section{Metodologia}

O experimento ocorreu na cidade de Pedro Avelino, RN. Foram utilizadas 3 baias coletivas (uma por tratamento), com medidas de $29 \mathrm{~m}^{2}$ cada, cimentadas, com metade coberta e outra com solário, dotadas de comedouro linear com 0,25 m/animal, saleiros e bebedouros coletivos.

Foram utilizados 24 cordeiros machos não castrados, sem padrão racial definido (SPRD), com 6 meses de idade e peso inicial de 20,9 \pm 1,0 Kg (8 animais por tratamento). Os tratamentos foram constituídos grão de milho inteiro associando ao suplemento comercial peletizado, com recomendações segundo o fabricante para utilização na engorda bovina com função protéicamineral-vitamínica, em três proporções de concentrado: volumoso, (100\%, 80:20\% e 60:40\%), sendo a porção concentrada da dieta composta de $85 \%$ de milho grão inteiro e $15 \%$ de suplemento e a porção volumosa de feno de Tifton. 
Os animais foram submetidos a três momentos de observações de seu comportamento, iniciando às cinco horas da manhã e se estendendo até às cinco horas da manhã do dia seguinte. $\mathrm{O}$ primeiro período de observações ocorreu cinco dias após o início do período experimental de confinamento e, subsequentemente, os próximos em intervalos de 14 dias entre cada pesagem. Durante este período os animais foram observados individualmente, a observação noturna dos animais foi realizada mediante o uso de iluminação artificial de lâmpadas incandescentes que foram acesas a noite durante todo o período experimental.

As avaliações consistiram em anotações das atividades do animal, de ingestão, ruminação e ócio. O método utilizado foi de scan sampling (varredura instantânea), realizado em intervalos iguais de 5 minutos durante 24 horas ininterruptas seguindo o método adotado por Johnson e Combs (1991). Após as coletas, os dados foram submetidos à análise de variância e as médias comparadas pelo teste Tukey, adotando-se o nível de significância de 5\%. As análises foram realizadas utilizando-se o pacote estatístico SAS (2004).

\section{Resultados e Discussões}

Não houve diferença $(\mathrm{P}>0,05)$ entre as dietas testadas para valores médios de consumo expressos em g/dia para matéria seca. Os resultados obtidos neste trabalho para consumo de matéria seca expressos em gramas/dia são inferiores aos preconizados pelo NRC (1985) que pode variar de 1,0 a 1,3 Kg/dia para essa categoria animal. Isso pode ser uma vantagem, quando o menor consumo não compromete o desempenho dos animais, assim como seu comportamento.

O tempo despendido para alimentação (TAL), foi superior nos cordeiros das dietas 60:40 e 80:20 \% quando comparado à dieta 100\% (Tabela 1). Isso se deve ao fato dos ruminantes reterem fibra no rúmen por um tempo adequado para digestão, devido à ingestão de partículas longas durante a alimentação. $\mathrm{O}$ tempo de ruminação (TRU) foi menor $(\mathrm{P}<0,05)$ (Tabela 1) nos cordeiros recebendo dietas $100 \%$, quando comparados aos demais tratamentos. Esse resultado pode ser explicado pelo menor teor de FDN e o maior teor de carboidratos não estruturais presente nessa dieta. Carvalho et al. (2004) descreveram que a ruminação é um recurso fisiológico acionado conforme a diminuição no tempo de alimentação para o melhor aproveitamento do alimento. No que concerne a busca pela sombra na execução da ruminação, em todos os tratamentos esse ato é bem representativo, pois o uso da sombra evita o estresse calórico (TUCKER et al., 2008). 
Tabela 1: Comportamento de ovinos SPRD alimentados com dietas de alto grão

\begin{tabular}{|c|c|c|c|c|c|}
\hline & \multicolumn{3}{|c|}{ Proporção de concentrado \% } & \multirow[t]{2}{*}{$\mathbf{C V}$} & \multirow[t]{2}{*}{$\mathbf{P}$} \\
\hline & 100 & 80 & 60 & & \\
\hline CMST & 0,675 & 0,592 & 0,523 & 23,54 & 0,20 \\
\hline TAL (h/dia) & $0,820 \mathrm{c}$ & $1,365 b$ & $2,414^{\mathrm{a}}$ & 33,63 & 0,0003 \\
\hline TRU (h/dia) & $2,690 b$ & $3,943^{\mathrm{a}}$ & $3,938^{\mathrm{a}}$ & 11,56 & $<0,0001$ \\
\hline TRU SOL & $0,126 b$ & $0,436^{\mathrm{a}}$ & $0,272 b$ & 11,05 & 0,049 \\
\hline TRU SOMBRA & $2,564 b$ & $3,507^{\mathrm{a}}$ & $3,666^{\mathrm{a}}$ & 7,33 & $<0,0001$ \\
\hline TOC (h/dia) & 14,75 & 13,31 & 11,81 & 18,44 & 0,1485 \\
\hline Água (h/dia) & $0,238 \mathrm{ab}$ & $0,140 b$ & $0,271^{\mathrm{a}}$ & 31,08 & 0,0110 \\
\hline
\end{tabular}

CMST: Consumo de matéria seca total em Kg/dia; TAL: Tempo de alimentação; TRU: Tempo de ruminação; TRU SOL: Tempo de ruminação ao sol; TRU SOMBRA: Tempo de ruminação na sombra; TOC: Tempo de ócio; Medias na mesma linha, seguidas de letras distintas diferem entre si pelo teste de Tukey, ao nível de 5\% de significância.

O tempo de ócio (TOC) (Tabela 1), foi maior nos animais inseridos no tratamento com o fornecimento da dieta 60:40\%, entretanto foi a conduta mais exercida entre todos os tratamentos, corroborando com a afirmação de Marques (2007), onde os animais com acesso a sombra, permanecem mais tempo exercendo tal conduta.

O consumo de água (Tabela 1) apresentou efeito $(\mathrm{P}<0,05)$, sendo maior nos animais que receberam a dieta 60:40\%, podendo esta atividade está ligada ao maior tempo de ruminação, atividade que gera calor metabólico.

\section{Conclusões}

A utilização da dieta com 100\% concentrado, garantiu ações básicas para o desenvolvimento das condutas comportamentais e fisiológica dos cordeiros.

\section{Referências}


CARDOSO, A.R. et al. Comportamento ingestivo de cordeiros alimentados com dietas contendo dif erentes níveis de fibra em detergente neutro. Ciência Rural, v.36, n.2, p.604-609, 2006.

CARVALHO, G.G.P.; PIRES, A.J.V.; SILVA, F.F. et al. Comportamento ingestivo de cabras leiteiras alimentadas com farelo de cacau ou torta de dendê. Pesquisa Agropecuária Brasileira, v.39, n.9, p.919-925, 2004.

COSTA, R. G. et al. Caracterização do sistema de produção caprino e ovino na região Semi-árida do estado da Paraíba. Brasil. Archivos de Zootecnia, Córdoba, v. 57, n. 218, p. 195-205, 2008.

COSTA, M.J.R.P. et al. Contribuição dos estudos de comportamento de bovinos para implementação de programas de qualidade de carne. In: XX Encontro Anual de Etologia, Sociedade Brasileira de Etologia, Anais... Natal-RN, 2002, p. 71-89.

COSTA, M.J.R.P. (1987). Comportamento dos animais de fazenda: reflexos na produtividade. In: Encontro Anual de Etologia, 5, Jaboticabal-SP, FCAV/UNESP, 1987, Anais... Jaboticabal-SP, FUNEP, 1987, p. 159-168.

DAMASCENO, J.C.; BACCARI JUNIOR, F.; TARGA, L.A. Respostas comportamentais de vacas holandesas com acesso a sombra constante ou limitada. Pes. Agropec. Bras., v.34, p.709-715, 1999.

JOHNSON, T.R.; COMBS, D.K. Effects of prepartum diet, inert rumen bulk, and dietary polythylene glicol on dry matter intake of lactating dairy cows. Journal of Dairy Science, v.74, n.3, p.933-944, 1991.

MARQUES, J.A. et al. Comportamento ingestivo de tourinhos confinados com ou sem acesso à sombra. Campo Digital. Campo Mourão, v. 2, n. 1, p. 43-49, jan./jun. 2007.

NATIONAL RESEARCH COUNCIL - NRC. Nutrient requirements of sheep. 6.ed. Washington, D.C.: National Academy Press, 1985.

SAS (2004) STATISTICAL ANALYSES SYSTEM - SAS. SAS/STAT user's guide. Cary: 2004.

SILANIKOVE, N. Effects of heat stress on the welfare of extensively managed domestic ruminants. Livestock Production Science, v. 67, n. 1-2, p. 1-18, 2000.

TUCKER, C.B.; ROGERS, A.R.; SCHÜTZ, K.E. Effect of solar radiation on dairy cattle behaviour, use of shade and body temperature in a pasture-based system. Applied Animal Behaviour Science, v. 109, p.141-154, 2008.

VECHIATO, T.A.F.; ORTOLANI, E.L. Dieta de alto grão VS urolitíase em pequenos ruminantes. 2008. Disponível em: <Disponível em: http://www.farmpoint.com.br/radares-tecnicos/

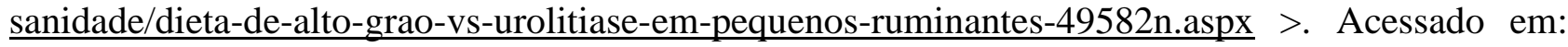
12 de setembro. 2017. 